\title{
Correspondence
}

\section{Sticking with Carrots and Sticks (Sticking Points Aside): A Response to Ventakapuram, Goldlberg, and Forrow}

\author{
Nir Eyal ${ }^{\star}$ \\ Department of Global Health and Social Medicine, Harvard Medical School, Boston, MA, USA
}

Received: 11 October 2013, Accepted: 22 October 2013, ePublished: 26 October 2013

$\mathrm{I}$ would like to thank Sridhar Ventakapuram, Daniel Goldberg, and Lachlan Forrow for thoughtful responses to my article (1-4). All endorse my main point, that conditioning the very aid that patients need in order to become healthier on their success in becoming healthier is (usually) wrong. They may think me, however, too friendly to an approach that gives patients "carrots" or "sticks" depending on how healthy their choices are. Ventakapuram writes, "What comes out of the article most clearly is that Eyal is fine with the carrots and sticks approach to health policy, he just wants to help clarify what should and should not be the carrots and sticks".

For the record, I have many problems with carrot and stick policies as such (5). Still, I believe that Ventakapuram's, Goldberg's, and Forrow's critiques of these policies are somewhat unfair, and will explain why.

According to Ventakapuram, my (imagined) "general agreement with carrot and stick policies does not sit right." Obese people, he argues, are "constrained", and that should inform the kind of policies directed at them, counting against carrot and stick policies. However, Ventakapuram only motivates this by showing that obese people are "constrained" in the sense that obesity constrains their lives, once they become obese ("obesity constrains individuals from being able to fully live their lives, most directly by leading to premature death"). While this is correct, it lends no support to Ventakapuram's critique of carrot and stick policies-which seek to remove constraints like premature death. Had he shown that obese patients are "constrained" in a different sense-that there is nothing that they could possibly do to lose weight—-then such policies would make no sense. But he has not shown that.

Ventakapuram warns, "carrots and stick policies have started to shift the focus of medicine away from the primary concern for the well-being of the patient. And from a public policy perspective, they conceptualize the citizen as a potential drain on public resources." But incentives and disincentives can be used to promote the patient's well-being, as well as to save money or achieve other goals. The tool of carrot and stick policies can serve various purposes. And as citizens and patients we are potential drains on the system. Providers and administrators of medicine should ration and save resources-to leave enough for underserved populations (including many non-patients and non-citizens) and important nonmedical goals.

Daniel Goldberg writes that the denial of treatment to obese patients is wrong (as are many other carrot and stick policies) because "it eschews a whole-population approach to the problem of poor nutrition and is therefore likely to be ineffective." But why assume it must altogether eschew such an approach? Surely we should pull all available levers to fight obesity: both "whole-population" policies (e.g. making lettuce cheaper than Mars bars) and carrot and stick policies (e.g. giving a prize to individuals who buy and consume lettuce and a penalty to those who buy Mars bars). Even if the fundamental causes of obesity lie upstream of individual choice, carrots and sticks can motivate individuals to protect themselves better from these causes (if we failed to make it cheaper to grow and transport lettuce, we can still subsidize lettuce-a carrot-or impose fat taxes on Mars bars-a stick).

Goldberg questions my take on policies that tackle obesity, smoking etc., through fat taxes, cigarette taxes, and the like. And he warns that carrot and stick policies can stigmatize patients. As he rightly points out, even if taxes and stigma improve health, they might wrack more socio-economic damage than the health improvement is worth. Nevertheless, they might also improve health and wellbeing far more than they wrack socioeconomic damage. For example, cigarette taxes and smoking zoning laws seem to work well against smoking and the related morbidity and mortality, arguably well enough to warrant the otherwise somewhat unfair socio-economic effects on smokers, including some stigma. Instead of having to endorse or reject this or that type of policy wholesale, we can accept that carrot and stick policies have a potential for worsening socioeconomic injustices, and so should be used only with care-roughly, when their good effect on health outweighs any bad effect in other departments. Lachlan Forrow writes at one point, "any conditions that the doctor imposes on [his or her] commitment to help [the patient] threaten the very nature of medicine". A response to my article on doctors who reject obese patients, this reads like a critique of any conditional treatment. Such a critique would seem unmotivated by Forrow's argument. What he argues, based on a case from his practice, is only that, "every patient needs and deserves a doctor who they know truly cares." As the case demonstrates, this is about the doctor's caring attitude (and oral expressions thereof), not primarily about her actions. Since offering incentives that encourage healthier choice can, according to Forrow, make "eminent sense from a policy perspective," why associate such conditioning with presumptive lack of caring or commitment to the patient's health? A critique of some motivations behind policy does not count against that policy.

*Corresponding author: Nir Eyal; Email: nir_eyal@hms.harvard.edu 
I should again add that it can actually be important for doctors to function as gatekeepers and guardians of public health, and not always as fierce advocates for their own patients. Absolute commitment to an individual patient-in action or attitude-is sometimes wrong (6).

Let me end with a concession and a refinement of my thesis. Ventakapuram's example of bariatric surgery is excellent, and it illustrates well that (as he puts it) the "rule of thumb" that I proposed is best understood as a "soft principle", which admits of exceptions. It is, therefore, only typically wrong to condition the very aid that patients need in order to become healthier on success in becoming healthier. Empirical evidence could establish whether such conditioning is promising in a given setting. What must not happen is that absent specific evidence for such policies in a given setting and without rapid impact assessments etc., such conditioning would roll out, on the false assumption that it usually works well. While I have elsewhere pointed to problems with personal responsibility for health policies, Ventakapuram, Goldberg, and Forrow overstate those problems. I remain grateful for their interesting replies to my piece.

Ethical issues

Not applicable.

Competing interests

The author declares that he has no competing interests.
Author's contribution

$\mathrm{NE}$ is the single author of the manuscript.

References

1. Venkatapuram S. There are many purposes for conditional incentives to accessing healthcare; Comment on "Denial of treatment to obese patients - the wrong policy on personal responsibility for health". International Journal of Health Policy and Management 2013; 1 : 235-6.

2. Goldberg DS. The errors of individualistic public health interventions: denial of treatment to obese persons; Comment on "Denial of treatment to obese patients-the wrong policy on personal responsibility for health". International Journal of Health Policy and Management 2013; 1: 237-8.

3. Forrow L. A doctor's first, and last, responsibility is to care; Comment on "Denial of treatment to obese patients-the wrong policy on personal responsibility for health". International Journal of Health Policy and Management 2013; 1: 239-40.

4. Eyal N. Denial of treatment to obese patients-the wrong policy on personal responsibility for health. International Journal of Health Policy and Management 2013; 1: 107-10.

5. Eyal N. Why treat noncompliant patients? Beyond the decent minimum account. $J$ Med Philos 2011; 36: 572-88.

6. Wendler D. Are physicians obligated always to act in the patient's best interests? J Med Ethics 2010; 36: 66-70. 